BMJ Open Sport \& Exercise Medicine

\title{
The effect of generalised joint hypermobility on rate, risk and frequency of injury in male university- level rugby league players: a prospective cohort study
}

Cassie Oddy, Mark I Johnson, Gareth Jones

\begin{abstract}
Background: Rugby league is a collision sport where musculoskeletal injuries are common. There has been little research on generalised joint hypermobility (GJH) as a risk factor for injury in rugby league. The aim of this study was to investigate the role of GJH on the incidence of injuries in first and second team rugby league players from one British university.
\end{abstract}

Methods: We conducted a prospective cohort study of 45 student players from one British university first and second team rugby league squads (mean age $20.93 \pm 1.57$ years). At the beginning of the season, GJH was determined using a 9-point Beighton scale, and injury and exposure data were collected on a weekly basis throughout the 2013-2014 season.

Results: The prevalence of GJH was $20 \%$. There was no statistically significant difference in the frequency of injuries between GJH and non-GJH participants ( $p=0.938$, Mann-Whitney $U$ test).Participants categorised as having GJH did not experience a higher fequency of injury ( $p=0.722$, Fisher's exact test) and there was no tendency to demonstrate a higher risk of injury for participants categorised as GJH (OR=0.64, $95 \% \mathrm{Cl} 0.15$ to 2.78; relative risk $(\mathrm{RR})=1.188,95 \% \mathrm{Cl}$ 0.537 to 2.625 ). The most common site of injury was the ankle, but this was not statistically significant (OR=0.152, 95\% Cl 0.008 to 2.876; $R R=0.195, \mathrm{Cl}$ 0.012 to 3.066 ).

Conclusion: British university rugby league players with GJH did not demonstrate a greater risk of injury than those without GJH.

\section{INTRODUCTION}

Rugby league is a collision sport where musculoskeletal injuries are common with the incidence of injury in professional rugby league players estimated to be between 34 and 52 injuries per 1000 playing hours. ${ }^{12}$ Risk factors for injury in rugby league include increased height, weight, body mass index (BMI) and level of play whereby slower decision making leads to a lower ability to avoid higher impact

\section{Key messages}

- Participants categorised as hypermobile did not demonstrate a higher incidence, frequency or risk of injury.

- We found no evidence to suggest generalised joint hypermobility (GJH) rugby league players are at more risk of knee injury.

- We suggest that clinicians should routinely screen their athletes for GJH.

tackles. $^{3-5}$ To date, there has been little research on generalised joint hypermobility $(\mathrm{GJH})$ as a risk factor for injury in rugby league.

Hypermobility refers to joint range of motion that exceeds normal limits. ${ }^{6} \mathrm{GJH}$ is a heritable connective tissue disorder characterised by hypermobility that exists in the absence of rheumatological pathology and musculoskeletal pain. ${ }^{78}$ Alteration in the structure of the protein collagen matrix of individuals with GJH may result in an individual sustaining joint damage due to dislocations, subluxations and sprains. ${ }^{9} 10$ Previously, we have reported that there is a greater incidence of injury in premiere league soccer players with GJH. In 2010, a meta-analysis of 18 prospective studies which evaluated the effect of GJH in a variety of sports and found that participants with GJH had an increased risk of knee joint injury during contact activities. ${ }^{10}$ The meta-analysis included two prospective cohort studies that investigated the incidence of injury and $\mathrm{GJH}$ in rugby union. ${ }^{11}$ ${ }^{12}$ Davies and Gibson ${ }^{11}$ found that $4 \%$ of 185 male players from 10 British Rugby Union clubs were categorised as having GJH using the original Beighton scale consisting of a 5 rather than 9-point scoring 
system. They concluded that GJH did not influence the incidence of injuries during a season. Stewart and Burden ${ }^{12}$ found that $24 \%$ of 51 male first division club rugby union players from New Zealand were categorised as having GJH using the 9-point Beighton scale. There was a higher incidence of injury throughout the season for players with GJH (116.7/1000 hours of exposure) compared with non-GJH players (43.6/1000 hours of exposure). Recently, Chalmers et al. ${ }^{5}$ conducted a prospective cohort study of 704 amateur rugby union players and found a greater risk of injury with increasing age, height and BMI. Forward players were injured more often and it was suggested that this may be because they are heavier.

Rugby union and rugby league differs in physical and technical demands. ${ }^{13}$ Rugby union Forwards tend to play at lower speeds than Backs. In contrast, Forwards and Backs play at higher speeds in rugby league and therefore they are exposed to more frequent highspeed collision tackles. ${ }^{14}{ }^{15}$ Such exposure may be a risk factor for injury as the majority of playing injuries occur in tackles with the tackled player sustaining more injuries than players affecting the tackles. ${ }^{3}$

There is a paucity of research investigating GJH and the prevalence and incidence of injuries in rugby league players. The aim of this study was to investigate the role of GJH on the incidence of injuries in first and second team rugby league players from one British university.

\section{METHODS}

\section{Design}

This was a prospective cohort study that used a sample of student rugby league players from one university first and second team rugby league squads over the 2013-2014 season.

\section{Recruitment of sample}

Rugby league players were verbally briefed about the nature of the study by the principal investigator (PI) before the first training session of the season. Players were given a written participant information pack that included a letter of invitation, details about the study, hazards associated with participation, limits of confidentiality and a consent form. Players who expressed interest in participation were asked to return signed consent forms at the next training session 48hours later. All squad players volunteered to participate in the study.

\section{Procedure}

Data were collected from match play and training for the entire season. All matches were competitive from both Premiere North league and cup fixtures for the duration of the British University and College Sport season (16 October 2013 to 30 March 2014). Data were also collected during training sessions and included rugby league-specific training and strength and conditioning.

\section{Baseline assessment}

Baseline assessment was undertaken by the PI before the first training session of the season and before the first competitive match, to minimise the presence of an injury (14 October 2013). The PI was a state-registered physiotherapist with experience of assessing musculoskeletal injury.

Measurements were taken in the 'club house' at the university. The following data were recorded:

Anthropometric measurements including age, height, weight and $\mathrm{BMI}-\mathrm{GJH}$ using a 9-point Beighton scale $(\text { Intraclass correlation coefficient }(\text { ICC })=0.96-0.98)^{16}$ that scores:

- Passive thumb flexion to oppose the flexor aspect of forearm (1 point for each thumb)

- Passive extension of fifth finger $>90^{\circ}$ ( 1 point for each finger)

- Elbow hyperextension $>10^{\circ}$ (1 point for each elbow)

- Passive hyperextension of knee $>10^{\circ}$ (1 point for each knee)

- Forward flexion of trunk, knees fully extended and palms placed flat on floor (1 point)

A cut-off point of $\geq 4$ out of 9 points was recorded as the presence of $\mathrm{GJH}$ as recommended by the British Society of Rheumatology. ${ }^{17}$

A single measurement of the range of motion of each of the joints using a $360^{\circ}$ plastic ISOM (International Standards of Measurement) goniometer as recommended by Smits-Engelsman et al. ${ }^{18}$

\section{Injury and exposure data}

Injury and exposure data were collected on a weekly basis (16 October 2013 to 30 March 2014) by the PI whom was not blind to hypermobility category. Training took place on Monday, Tuesday, Thursday and Friday. The training schedule included a $45 \mathrm{~min}$ wrestling session on Monday, $90 \mathrm{~min}$ rugby specific training on Tuesday, 60 min swimming session on Thursday and a 60 min strength and conditioning session on Friday. Matches took place on a Wednesday with match duration being $80 \mathrm{~min}$. The PI met with team players and support staff (coach) each week on the day before a game (usually Tuesday).

\section{Injury data}

Injury was defined according to a consensus of international researchers described in King et al ${ }^{1}$ as 'Any pain or disability that occurs during participation in a rugby league match or training activities that is sustained by a player, irrespective of the need for match or training time loss or for first aid or medical attention'. This definition includes medical attention and time-loss injuries so that data gathered can be compared within and between sports. Thus, an injury 
was recorded if it resulted in the player missing the subsequent training session or game. Players who met the criteria for injury were asked to complete an injury reporting form that is used by Sports Medicine Australia to document injuries for various sports including rugby league. ${ }^{1}$ The injury reporting form categorised injury severity in relation to the number of days of modified activity (slight (0 days), minimal (1-3 days), mild (4-7 days), moderate (8-28 days) and severe ( $>28$ days).

\section{Exposure data}

The total time of training and matches was calculated for each player per week and documented in a monthly injury exposure form. If a player had reported an injury and/or had been absent from training or a match for any reason, this time lost was subtracted from the total weekly exposure.

\section{Data management and analysis}

Baseline data were analysed using descriptive statistics. Comparisons between participants with and without $\mathrm{GJH}$ for demographic, anthropometric and exposure data were made using unpaired two-tailed t-tests or Mann-Whitney U tests if data did not meet the assumption of normality. Comparisons of injury frequency counts were made using a Fisher's exact test as the number of players sustaining at least one injury. The influence of hypermobility as a potential predictor variable for risk of injury was analysed by OR and relative risk (RR) analyses. RR and ORs were calculated using a $2 \times 2$ contingency table for the number of players sustaining at least one injury between GJH and non$\mathrm{GJH}$ players. Injury rate was calculated as the number of injuries/1000-hour exposure using the following equation: [Number of injuries/exposure (hours)] $\times$ $1000=$ Number of injuries/1000-hour exposure. Analysis was performed using SPSS version 21, with statistical significance set at $\mathrm{p}<0.05$.

\section{RESULTS}

\section{Characteristics of study group}

There were 45 male participants that provided preseason assessment data (mean $\pm \mathrm{SD}$ age, $20.93 \pm 1.57$ years). Mean Beighton score was $1.62 \pm 2.03$ out of a maximum score of 9 . The prevalence of GJH was $20 \%$ with nine participants scoring 4 or more on the Beighton scale. There were no statistically significant differences between GJH and non-GJH participants in age, height, weight, BMI, total exposure, training exposure and match exposure (table 1).

\section{Analysis of injuries}

A total of 33 injuries were recorded during the season. No participant sustained a re-injury (ie, at the same anatomical site). Twenty-three of the 45 participants (51\%) sustained at least 1 injury (4 GJH participants $(8$ injuries) and 19 non-GJH participants (25 injuries)). There was no tendency to experience injury for participants categorised as having GJH $(4 / 9 \quad \mathrm{GJH}$ participants, 9/36 non-GJH participants, $p=0.722$, Fisher's exact test). There was no tendency to demonstrate a higher risk of injury for participants categorised as $\mathrm{GJH}(\mathrm{OR}=0.64,95 \%$ CI 0.15 to 2.78; $\mathrm{RR}=1.188,95 \%$ CI 0.537 to 2.625 ). There was no statistically significant difference in the frequency of injuries between GJH and non-GJH participants $(\mathrm{p}=0.938$, Mann-Whitney $\mathrm{U}$ test $)$. There were no statistically significant differences between GJH and non$\mathrm{GJH}$ participants in mean incidence rate of all injuries $(\mathrm{p}=0.821$, Mann-Whitney $\mathrm{U}$ test $)$ or injuries during training $(\mathrm{p}=0.523$ Mann-Whitney $\mathrm{U}$ test) or match play ( $\mathrm{p}=0.678$, Mann-Whitney U test).

The severity of injuries was mild $(26 / 33,78.8 \%)$, moderate $(5 / 33,15.1 \%)$ and severe $(2 / 33,6.1 \%)$. There were no statistically significant differences between $\mathrm{GJH}$ and non-GJH participants in injury severity for each category (table 2). Injuries were sustained at seven different body sites with the most common site being the ankle $(11 / 33,33 \%)$ and knee $(10 / 33,30 \%$; table 3$)$.

Table 1 Demographic and anthropometric data

\begin{tabular}{|c|c|c|c|c|}
\hline & All participants & Hypermobile & Non-hypermobile & $\mathbf{p}$ \\
\hline Number of participants & 45 & 9 & 36 & \\
\hline Beighton score & $1.62 \pm 2.03$ & $5.00 \pm 1.50$ & $0.78 \pm 0.99$ & $<0.001$ \\
\hline Age (years) & $20.93 \pm 1.57$ & $20.56 \pm 1.42$ & $21.03 \pm 1.61$ & $0.427^{\ddagger}$ \\
\hline Height (cm) & $179 \pm 0.06$ & $175 \pm 0.07$ & $180 \pm 0.06$ & 0.079 \\
\hline Weight (kg) & $88.57 \pm 13.87$ & $81.42 \pm 14.49$ & $90.35 \pm 14.61$ & $0.084^{\ddagger}$ \\
\hline Body mass index $\left(\mathrm{kg} / \mathrm{m}^{2}\right)$ & $27.75 \pm 3.75$ & $26.62 \pm 2.74352$ & $28.04 \pm 3.94$ & $0.317^{\ddagger}$ \\
\hline Training exposure (hours) & $113.71 \pm 12.48$ & $107.69 \pm 24.40$ & $115.22 \pm 6.94$ & $0.386^{\ddagger}$ \\
\hline Match exposure (hours) & $10.84 \pm 6.49$ & $11.70 \pm 11.54$ & $10.63 \pm 4.71$ & $0.662^{\ddagger}$ \\
\hline Total exposure (training + match) (hours) & $124.56 \pm 14.07$ & $119.40 \pm 27.19$ & $125.85 \pm 8.46$ & $0.501^{\ddagger}$ \\
\hline
\end{tabular}


Table 2 Analysis of injuries

\begin{tabular}{|c|c|c|c|c|}
\hline & All participants & Hypermobile & Non-hypermobile & $\mathbf{p}$ \\
\hline $\begin{array}{l}\text { Total incidence of injury } \\
\text { (training }+ \text { match), per } 1000 \text { hours }\end{array}$ & $6.19 \pm 8.18$ & $8.77 \pm 13.33$ & $5.54 \pm 6.42$ & $0.821^{\dagger}$ \\
\hline Incidence of training injuries, per 1000 hours & $3.38 \pm 7.36$ & $6.98 \pm 14.39$ & $2.48 \pm 4.07$ & $0.523^{\dagger}$ \\
\hline Incidence of match injuries, per 1000 hours & $46.40 \pm 118.75$ & $31.25 \pm 66.29$ & $50.19 \pm 129.04$ & $0.678^{\dagger}$ \\
\hline Number of injuries during training + match play per player (tally) & 33 & 8 & 25 & $0.867^{\ddagger}$ \\
\hline Injury severity mild (1-7 days modified activity) & 26 & 7 & 19 & $0.652^{\S}$ \\
\hline Injury severity moderate (8-21 days modified activity) & 5 & 0 & 5 & $0.241^{\S}$ \\
\hline Injury severity severe ( $>21$ days modified or lost activity) & 2 & 1 & 1 & $0.283^{\S}$ \\
\hline
\end{tabular}

It was noteworthy that no participant categorised as having GJH sustained an ankle injury, but this was not statistically significant $\quad(\mathrm{OR}=0.152, \quad 95 \% \quad \mathrm{CI}$ 0.008 to $2.876 ; \mathrm{RR}=0.195$, CI 0.012 to 3.066$)$. Types of injury included ligamentous sprains (11/33, 33.3\%), muscle strains $(8 / 33,24.2 \%)$, inflammation/swelling (5/ $33,15.2 \%)$, overuse injuries $(4 / 33,12.1 \%)$, dislocations $(3 / 33,9.1 \%)$ and bruises/contusions $(2 / 33,6.1 \%)$.

\section{DISCUSSION}

\section{Statement of principle findings}

There is a paucity of research on $\mathrm{GJH}$ as a risk factor for injury in rugby league. This study found that the prevalence of $\mathrm{GJH}$ in a sample of 45 male rugby league players was $20 \%$, with no statistically significant differences between GJH and non-GJH participants in the frequency of injuries or incidence rate of injury per 1000 hours. The findings suggest that GJH is not a risk factor for injury in rugby league, although this inference is made from a single site study, with relatively small sample size and low incidence of injuries. The findings of this study should be used to inform the design of a large, multisite prospective study.

\section{Meaning of study findings}

Research from sports rehabilitation fails to provide a consensus about the role of $\mathrm{GHJ}$ as a risk factor for

Table 3 Location of injury

\begin{tabular}{llll}
\hline Type & $\begin{array}{l}\text { All } \\
\text { participants }\end{array}$ & Hypermobile & $\begin{array}{l}\text { Non- } \\
\text { hypermobile }\end{array}$ \\
\hline Hamstring & 4 & 2 & 2 \\
Thigh & 1 & 0 & 1 \\
Ankle & 11 & 0 & 11 \\
Knee & 10 & 4 & 6 \\
Hip & 2 & 1 & 1 \\
Shoulder & 4 & 1 & 3 \\
Lower & 1 & 0 & 1 \\
back & & & \\
\hline
\end{tabular}

injury. We estimated the prevalence of GJH to be $20 \%$, which is slightly higher than that reported for the general population (ie, $5 \%-15 \%^{17}$ ) but within the range reported for sporting populations (ie, $5 \%-43 \%{ }^{7}$ ). A systematic review of 18 studies by Pacey et al. ${ }^{10}$ found that $\mathrm{GJH}$ was a risk factor for injuries to the knee but not the ankle in contact sports. The systematic review did not include any studies on rugby league but did include two studies on rugby union. ${ }^{11}{ }^{12}$ One of these studies investigated 185 first-class English and Welsh players and found that GJH did not increase the risk of injury in rugby union players, ${ }^{11}$ consistent with our findings. In contrast, Stewart and Burden ${ }^{12}$ studied 51 first-class players from New Zealand and found that GJH increased the risk of injury. They used very similar methodology to that used in our study. They estimated prevalence of GJH to be $24 \%$ using a Beighton score of $\geq 4 / 9$ as the cut point, and they documented 33 injuries over the season. These findings are remarkably similar to ours. However, they found a statistically significant difference in injury rates between $\mathrm{GJH}$ and non-GJH players. In addition, anthropometric measures such as height, weight and BMI are considered as potential risk factors for injury in rugby league, ${ }^{4} 5{ }^{19}$ yet we found no statistically significant differences in height, weight and BMI between players with and without GJH. We also found no evidence to suggest $\mathrm{GJH}$ rugby league players are at more risk of knee injuries than non-hypermobile players.

Of interest was our finding that the ankle was the most common site of injury yet no participants with GJH sustained an ankle injury. A systematic review of predictors for ankle injury found that reduced mobility of the ankle strongly predicted ankle sprain injuries. ${ }^{20}$ The biomechanical and anatomical differences between joints and the structural differences in the collagen matrix may mean that some joints are more susceptible to injury than others in those individuals categorised as hypermobile. Thus, we speculate that hypermobility 
may be beneficial to reduced injury occurrence at some joints.

\section{Limitations of study}

The small sample sizes used in studies including ours may be responsible in part for this discrepancy in findings. Interpretation of study findings across studies investigating $\mathrm{GJH}$ can be difficult because of variability in methods used to categorise $\mathrm{GJH}$, define injury occurrence and monitor exposure. We used the 9-point Beighton scale because it is has been validated for use in athletic populations and recommended by the British Society of Rheumatology. ${ }^{17}$ However, the Beighton scale gives credence to hypermobility in upper limbs and this limits its applicability for hypermobility in lower limbs and their associated injuries. It is noteworthy that hypermobility of the ankle is not assessed. The Brighton criteria incorporates the Beighton scale but also recognises additional symptoms and other characteristics associated with connective tissue laxity. ${ }^{21}$ Previously, it has been argued that exclusive use of the Beighton scale may lead to the incorrect categorisation of a player as non-hypermobile when their medical history may suggest otherwise. ${ }^{22}$

Moreover, inconsistency in criteria used to categorise type of injury may lead to under-reporting or over reporting of specific injuries and inconsistency in tallies of injuries at multiple body sites and/or repeated injuries (ie, re-injury) reducing confidence in interpretation of findings. This is further compounded by the introduction of measurement errors due to imprecise recording, interpretation, calculation and recollection of injury occurrence, injury mechanism and both training and match play exposure. These limitations coupled with variability in study design combined with unclear and superficial reporting of study operational details make between-study comparisons of injury incidence difficult.

\section{Implications for clinicians and improvements to service}

Our findings suggest that $\mathrm{GJH}$ does not contribute to injury risk in rugby league. Nevertheless, we are reluctant to recommend that practitioners should not screen rugby league players for GJH. The reasons why we recommend that players should still be screened for GJH include limitations associated with this and previous studies; the paucity of research into risk factors for injury in rugby league; and identifying players with GJH may be useful for specific rehabilitative strategies and return to play timescales. Moreover, there is strong evidence that $\mathrm{GJH}$ is a risk factor in other contact sports including soccer, although evidence is conflicting for rugby union. ${ }^{1023}$ We suggest that screening for GJH should use the Brighton scale as it provides both a Beighton score and considers the overall health of the individual.

\section{Future research}

There is a clear need for a large-scale multisite (multiteam) prospective cohort study to investigate risk factors associated with injury in rugby league. Consideration should be given to the limitations encountered in our study, and particular attention should be given to obtaining accurate data for exposure as described previously. ${ }^{23}$ Players should be categorised for GJH according to the Brighton criteria to improve accuracy and precision of classification but also using the Beighton to enable comparison with previous studies that tend to use the Beighton scale.

\section{Conclusion}

British university rugby league players with GJH did not demonstrate a greater risk of injury than those without GJH.

Contributors CO: Planned, designed submitted forms for ethical approval, carried out data collection, analysed data, write up of study and preparation and submission of manuscript. MIJ: Proof-reading and editing of manuscript. GJ: Statistical analysis and preparation of manuscript.

Competing interests None declared.

Ethics approval Ethical approval was sought through the University of Salford-College Ethics Panel 2014.

Data sharing statement Research materials related to the paper including data can be accessed by contacting the corresponding author CO.Article Provenance and peer reviewNot commissioned; externally peer reviewed

Open Access This is an Open Access article distributed in accordance with the Creative Commons Attribution Non Commercial (CC BY-NC 4.0) license, which permits others to distribute, remix, adapt, build upon this work noncommercially, and license their derivative works on different terms, provided the original work is properly cited and the use is non-commercial. See: http:// creativecommons.org/licenses/by-nc/4.0/

\section{REFERENCES}

1 King DA, Gabbett TJ, Gissane C, et al. Epidemiological studies of injuries in rugby league: suggestions for definitions, data collection and reporting methods. J Sci Med Sport 2009;12:12-19.

2 Gabbett TJ. Influence of training and match intensity on injuries in rugby league. J Sports Sci 2004;22:409-17.

3 Gabbett TJ. Incidence of injury in semi-professional rugby league players. Br J Sports Med 2003;37:36-43. discussion 43-4.

4 Quarrie KL, Alsop JC, Waller AE, et al. The New Zealand rugby injury and performance project. VI. A prospective cohort study of risk factors for injury in rugby union football. $\mathrm{Br} J$ Sports Med 2001;35:157-66.

5 Chalmers DJ, Samaranayaka A, Gulliver P, et al. Risk factors for injury in rugby union football in New Zealand: a cohort study. $\mathrm{Br} J$ Sports Med 2012;46:95-102.

6 Russek LN. Hypermobility syndrome. Phys Ther 1999;79:591-9.

7 Simmonds JV, Keer RJ. Hypermobility and the hypermobility syndrome. Man Ther 2007;12:298-309.

8 Simpson MR. Benign joint hypermobility syndrome: evaluation, diagnosis, and management. J Am Osteopath Assoc 2006;106:5316.

9 Adib N, Davies K, Grahame R, et al. Joint hypermobility syndrome in childhood. A not so benign multisystem disorder? Rheumatology 2005;44:744-50.

10 Pacey V, Nicholson LL, Adams RD, et al. Generalized joint hypermobility and risk of lower limb joint injury during sport: a systematic review with meta-analysis. Am J Sports Med 2010;38:1487-97.

11 Davies JE, Gibson T. Injuries in Rugby Union football. Br Med J 1978;2:1759-61. 
12 Stewart DR, Burden SB. Does generalised ligamentous laxity increase seasonal incidence of injuries in male first division club rugby players? Br J Sports Med 2004;38:457-60.

13 Austin D, Gabbett T, Jenkins D. Repeated high-intensity exercise in professional rugby union. J Sports Sci 2011;29:1105-12.

14 Brown SR, Brughelli M, Griffiths PC, et al. Lower-extremity isokinetic strength profiling in professional rugby league and rugby union. Int $J$ Sports Physiol Perform 2014;9:358-61.

15 Gabbett TJ. Science of rugby league football: a review. J Sports Sci 2005;23:961-76.

16 Evans AM, Rome K, Peet L. The foot posture index, ankle lunge test, Beighton scale and the lower limb assessment score in healthy children: a reliability study. J Foot Ankle Res 2012;5:1.

17 Remvig L, Jensen DV, Ward RC. Are diagnostic criteria for general joint hypermobility and benign joint hypermobility syndrome based on reproducible and valid tests? A review of the literature. $J$ Rheumatol 2007;34:798-803.
18 Smits-Engelsman B, Klerks M, Kirby A. Beighton score: a valid measure for generalized hypermobility in children. J Pediatr 2011;158:119-23.

19 Gabbett TJ, Ullah S, Finch CF. Identifying risk factors for contact injury in professional rugby league players-application of a frailty model for recurrent injury. J Sci Med Sport 2012;15:496-504.

20 Denegar CR, Miller SJ 3rd. Can chronic ankle instability be prevented? Rethinking management of lateral ankle sprains. J Athl Train 2002;37:430-5.

21 Grahame R, Bird HA, Child A. The revised (Brighton 1998) criteria for the diagnosis of benign joint hypermobility syndrome (BJHS). $J$ Rheumatol 2000;27:1777-9.

22 Konopinski M, Graham I, Johnson MI, et al. The effect of hypermobility on the incidence of injury in professional football: a multi-site cohort study. Phys Ther Sport 2016;21:7-13.

23 Konopinski MD, Jones GJ, Johnson MI. The effect of hypermobility on the incidence of injuries in elite-level professional soccer players: a cohort study. Am J Sports Med 2012;40:763-9. 